\title{
Genome-wide analysis of the three-way interplay among gene expression, estrogen receptor expression and chemotherapeutic sensitivity in breast cancer
}

\author{
DONG-XU HE ${ }^{1 *}$, XIAO-LI WU ${ }^{1 *}$, CHUN-XIAO LU ${ }^{1}$, XIAO-TING GU ${ }^{1}$, \\ GUANG-YUAN ZHANG ${ }^{1}$, XIN MA $^{1}$ and DE-QUAN LIU ${ }^{2}$ \\ ${ }^{1}$ National Engineering Laboratory for Cereal Fermentation Technology and Wuxi Medical School, \\ Jiangnan University, Wuxi, Jiangsu 214122; ${ }^{2}$ Department of Breast Surgery, The Third Affiliated Hospital, \\ Kunming Medical University, Kunming, Yunnan 650031, P.R. China
}

Received April 7, 2017; Accepted September 26, 2017

DOI: 10.3892/or.2017.6033

\begin{abstract}
The expression of estrogen receptor $\alpha$ (ER) in breast cancers may be indicative of a favorable prognosis and most of these cancers respond to anti-estrogens or aromatase inhibitors. However, ER-positive $\left(\mathrm{ER}^{+}\right)$breast cancers receiving anti-hormone and/or chemotherapy sometimes lose their ER expression, which leads to the evolution of the disease to higher aggressiveness and drug resistance. In the present study, an ER-modified signature (EMS) was developed from the expression profile of a chemoresistant MCF-7 breast cancer cell line that lost ER expression during long-term treatment with a chemotherapeutic agent. The EMS could discriminate the ER-negative (ER') breast cancer cells from the $\mathrm{ER}^{+}$ones, which included seven pathways essential for the ER ${ }^{-}$cell development. Furthermore, the EMS indicated a more malignant subgroup of the ER- cells by discriminating the chemoresistant ER cells from the chemosensitive ones. In addition, the classified chemoresistant ER patients demonstrated worse prognosis. In conclusion, we developed a new method to discriminate subgroups of $\mathrm{ER}^{-}$breast cancer cells.
\end{abstract}

Correspondence to: Dr Xin Ma, Wuxi Medical School, Jiangnan University, Wuxi, Jiangsu 214122, P.R. China

E-mail:maxin@jiangnan.edu.cn

Dr De-Quan Liu, Department of Breast Surgery, The Third Affiliated Hospital, Kunming Medical University, Kunming, Yunnan 650031, P.R. China

E-mail: dequanliu08@163.com

*Contributed equally

Key words: estrogen receptor $\alpha$, breast cancer, chemoresistance, signature

\section{Introduction}

Estrogen receptor $\alpha(E R)$ is a ligand-activated transcription factor that is activated by the hormone estrogen (17 $\beta$-estradiol) to regulate processes in the reproductive tract, the mammary gland as well as the skeletal and cardiovascular system. ER is also important in tumorigenesis, especially in breast carcinomas where it is involved in a wide range of critical signaling pathways such as cell growth and differentiation.

Clinically, the ER status is one of the most important molecular classification schemes in breast cancer. About two-thirds of all breast cancer patients overproduce ER (ER-positive, ER ${ }^{+}$) at the time of diagnosis and $60-70 \%$ of them respond well to anti-hormone agents such as tamoxifen and anastrazole (1). These patients often have a good prognosis when concomitantly treated with other chemotherapeutic agents $(2,3)$.

However, some $\mathrm{ER}^{+}$breast cancer patients receiving antihormone and/or chemotherapy lose function or expression of the ER during the clinical evolution of the disease (4-6). With a low or absent ER expression (ER-negative, ER') and a lack of ER-dependent cancer cell growth, the tumors are associated with a non-differentiated phenotype, a high cell-proliferation index and high aggressiveness, which in turn lead to a high rate of poor responses to a second round of therapy and a worse prognosis than the ER group diagnosed before any treatment $(7,8)$. Therefore, breast cancer cells that transform from $\mathrm{ER}^{+}$to $\mathrm{ER}^{-}$may display unique gene expression patterns that are associated with high malignancy, including aggressiveness and drug resistance. Clarifying these patterns may provide a way to identify a more malignant subgroup of cells among the total ER population.

Microarray and next-generation sequencing technologies provide a window into the global gene expression changes in cancer cells. Previously, numerous studies have sought for gene-expression patterns that distinguish between $\mathrm{ER}^{+}$and the ER breast cancer cells which were either collected from $\mathrm{ER}^{+}$and $\mathrm{ER}^{-}$breast cancer patients $(9,10)$, or from ER-silenced breast cancer cells $(11,12)$. However, no study has analyzed the differences in gene expression between anti-hormone or chemotherapy-induced ER cells and their parental $\mathrm{ER}^{+}$cells. 
Therefore, in order to understand the changes in gene expression and cell signaling during treatment-induced loss of ER and aiming to develop an indicator for the more malignant subgroup of ER- cells, an ER-modified signature (EMS) was developed from the expression profile of a chemoresistant MCF-7 breast cancer cell line that lost ER during long-term treatment with a chemotherapeutic agent. The EMS not only discriminated the $\mathrm{ER}^{-}$from $\mathrm{ER}^{+}$ breast cancer cells, but it was also sensitive in indicating the chemoresponse of the ER' patients.

\section{Materials and methods}

Cell lines. ER- MCF-7 cells (MCF-7/ADM) that are chemoresistant (13), highly aggressive (13-16) and exhibit properties of epithelial-mesenchymal transition (17) were derived by treating normal MCF-7 cells [(MCF-7/wild-type (WT)] (American Type Culture Collection, Manassas, VA, USA) with stepwise increasing concentrations of Adriamycin (ADM, from 0.01 to $250 \mu \mathrm{M}$ ) over 8 months as we previously described (13). Both the MCF-7/WT and the MCF-7/ADM cells were cultured in RPMI-1640 medium (Gibco; Thermo Fisher Scientific, Inc., Waltham, MA, USA) supplemented with $10 \%$ ( $\mathrm{vol} / \mathrm{vol}$ ) fetal bovine serum (FBS), $100 \mu \mathrm{g} / \mathrm{ml}$ penicillin and $100 \mathrm{U} / \mathrm{ml}$ streptomycin. The half maximal inhibitory concentrations $\left(\mathrm{IC}_{50} \mathrm{~s}\right)$ of $\mathrm{ADM}$ were $5.2 \pm 4.8$ and $67 \pm 17.7 \mu \mathrm{M}$ in the MCF-7/WT and the MCF-7/ADM cells, respectively $(13,15-17)$.

Western blot analysis. The total proteins of the MCF-7/ADM and the MCF-7/WT cells were extracted using the CytoBuster ${ }^{\mathrm{TM}}$ Protein Extraction Reagent (Novagen, Madison, WI, USA) at $4^{\circ} \mathrm{C}$. Subsequently, the proteins were resolved by $10 \%$ SDS-PAGE and transferred electrophoretically (at $100 \mathrm{~V}$, for $1 \mathrm{~h}$ ) onto polyvinylidene difluoride membranes, which were blocked (for $1 \mathrm{~h}$, at $20^{\circ} \mathrm{C}$ ) with $3 \%$ bovine serum albumin (BSA). The membranes were then incubated with the primary antibody, anti-human estrogen receptor alpha (ab75635, 1:2,000 dilution; Abcam, Cambridge, MA, USA) overnight at $4^{\circ} \mathrm{C}$. Anti-GAPDH (ab9483, 1:1,000 dilution; Abcam) was used as a loading control. After incubation with the proper secondary antibodies, antibody binding was detected with an Odyssey Imaging system (LI-COR Biosciences, Lincoln, NE, USA).

RNA sequencing and data deposition. The total RNA of the MCF-7/ADM and the MCF-7/WT cells was extracted with TRIzol reagent (Invitrogen Life Technologies, Carlsbad, CA, USA) according to the manufacturer's protocol. The quality of RNA was determined by rRNA ratio $(28 \mathrm{~S} / 18 \mathrm{~S})$ and the RNA integrity number (RIN) was assessed with Agilent 2100 Bioanalyzer (Agilent Technologies, Inc., Santa Clara, CA, USA). RNAs with $28 \mathrm{~S} / 18 \mathrm{~S}=2$ and $\mathrm{RIN}=9$ were sequenced on an Illumina HiSeq2000 (Illumina, Inc., San Diego, CA, USA). The raw data and the RNA-sequencing of the MCF-7 cells were deposited in the Gene Expression Omnibus (GEO) database (GSE68815): http://www.ncbi.nlm.nih.gov/geo/query/acc. cgi?acc $=$ GSE68815.

Summary of public datasets. We collected publicly available datasets of breast cancer cells and clinical breast cancer samples from GEO. The gene expression of these cells and samples was produced by whole-genome microarrays (Table I).

Statistical analysis. Hierarchical clustering was performed with Cluster 3.0 (University of Tokyo, Human Genome Center, Tokyo, Japan) and TreeView software (Stanford University, Stanford, CA, USA). The Bayesian binary regression analysis using leave-one-out cross-validation in SPSS was used to assess the validity and robustness of the EMS in distinguishing the two phenotypic states (27-32). The performance of EMS was evaluated by the area under the receiver operating characteristic (ROC) curve (AUC, Matlab; MathWorks, Inc., Natick, MA, USA). The distant relapse-free survival (DRFS) and the relapsefree survival (RFS) were analyzed by the Kaplan-Meier method and compared with the log-rank method (GraphPad Prism software; GraphPad Software, Inc., La Jolla, CA, USA). Odds ratios (ORs) for death events were calculated using the Review Manager software (The Cochrane Collaboration, Copenhagen, Denmark) to yield forest plots. The Kyoto Encyclopedia of Genes and Genomes (KEGG) and the Gene Ontology (GO) analysis were processed in the WebGestalt website (http://www. webgestalt.org/option.php).

\section{Results}

Generating the EMS. We used a previously developed MCF-7 cell line (MCF-7/ADM) and its parental control line (MCF-7/WT) as the basis of the signature development. The MCF-7/ADM cells were ER (Fig. 1A) and much more resistant to ADM than the MCF-7/WT cells (13). Therefore, the gene-expression profile of the MCF-7/ADM cells contained information about chemoresistance in ER- breast cancer cells (NCBI database: GSE68815). When the gene-expression profile of the ER ${ }^{-}$and chemoresistant MCF-7/ADM cells was compared with that of the $\mathrm{ER}^{+}$and chemosensitive MCF-7/WT cells, $>5,000$ genes were found with fold changes $>2$.

Subsequently, GSE27473 (11) was used to refine the list of genes. The ERs in the MCF-7 cells in this dataset were silenced by siRNA, so the silenced cells may present features typical of ER-related signals. Within GSE27473, >300 genes were found with a fold change $>2$ in the ER-silenced MCF-7 cells compared with the control cells. Subsequently, the selected genes from GSE68815 and GSE27473 were integrated to generate the 105-gene EMS (Fig. 1B, step 1; Fig. 1C, the list of genes is not shown in the present study).

EMS discriminates between the $E R^{-}$and $E R^{+}$breast cancer cells. In order to validate the postulate that the EMS represents the basic features of ER- breast cancer cells (Fig. 1B, step 2), the ability of EMS to discriminate the $\mathrm{ER}^{+}$from the ER- breast cancer cells was assessed by hierarchical clustering with dataset GSE6569 (18), which contains gene expression profiles of different breast cancer cell lines. As a result, all the breast cancer cells were correctly grouped according to their ER status (Fig. 2A).

The discriminative power of EMS was then validated in 279 clinical samples from GSE41998 (19), which recorded the $\mathrm{ER}$, the progesterone receptor (PR) and the human epidermal growth factor receptor 2 (Her2) status of each patient. The 
Table I. Publicly available gene expression data analyzed in the present study.

\begin{tabular}{|c|c|c|c|c|c|}
\hline $\begin{array}{l}\text { GEO data source and } \\
\text { web site address }\end{array}$ & Study (ref.) & Platform & $\begin{array}{c}\text { Sample } \\
\text { description }\end{array}$ & $\begin{array}{l}\text { Chemo } \\
\text { regime }\end{array}$ & $\begin{array}{l}\text { Application } \\
\text { in this study }\end{array}$ \\
\hline $\begin{array}{l}68815 \\
\text { https://www.ncbi.nlm.nih.gov/ } \\
\text { geo/query/acc.cgi?acc=gse } 68815\end{array}$ & $\begin{array}{l}\text { Developed } \\
\text { in this study }\end{array}$ & $\begin{array}{c}\text { Illumina } \\
\text { HiSeq2000 }\end{array}$ & $\begin{array}{l}\text { Chemotherapy- } \\
\text { induced ER loss } \\
\text { in MCF- } 7 \text { cells }\end{array}$ & Adriamycin & Develop EMS \\
\hline $\begin{array}{l}27473 \\
\text { https://www.ncbi.nlm.nih.gov/ } \\
\text { geo/query/acc.cgi?acc=gse } 27473\end{array}$ & Al Saleh et al (11) & GPL570 & $\begin{array}{l}\text { ER-silenced } \\
\text { MCF-7 cells }\end{array}$ & N/A & Develop EMS \\
\hline $\begin{array}{l}6569 \\
\text { https://www.ncbi.nlm.nih.gov/ } \\
\text { geo/query/acc.cgi?acc=gse } 6569\end{array}$ & Huang et al (18) & GPL96 & $\begin{array}{l}\mathrm{ER}^{+} \text {or } \mathrm{ER}^{-} \text {breast } \\
\text { cancer cell lines }\end{array}$ & N/A & $\begin{array}{l}\text { Validate } \\
\text { discriminative } \\
\text { power EMS }\end{array}$ \\
\hline $\begin{array}{l}54326 \\
\text { https://www.ncbi.nlm.nih.gov/ } \\
\text { geo/query/acc.cgi?acc=gse } 54326\end{array}$ & N/A & GPL10558 & $\begin{array}{l}\text { ER }^{-} \text {chemoresistant } \\
\text { and sensitive breast } \\
\text { cancer cell lines }\end{array}$ & Epirubicin & $\begin{array}{l}\text { Validate } \\
\text { predictive } \\
\text { power of EMS }\end{array}$ \\
\hline $\begin{array}{l}41998 \\
\text { https://www.ncbi.nlm.nih.gov/ } \\
\text { geo/query/acc.cgi?acc=gse } 41998\end{array}$ & Horak et al (19) & GPL571 & $\begin{array}{l}\text { Breast cancer } \\
\text { samples }\end{array}$ & $\begin{array}{l}\text { Doxorubicin and } \\
\text { cyclophosphamide }\end{array}$ & $\begin{array}{l}\text { Validate } \\
\text { discriminative } \\
\text { and predictive } \\
\text { power of EMS }\end{array}$ \\
\hline $\begin{array}{l}6861 \\
\text { https://www.ncbi.nlm.nih.gov/ } \\
\text { geo/query/acc.cgi?acc=gse } 6861\end{array}$ & Bonnefoi et al (20) & GPL1352 & $\begin{array}{l}\text { Breast cancer } \\
\text { samples }\end{array}$ & $\begin{array}{l}\text { 5-Fluorouracil, } \\
\text { cyclophosphamide } \\
\text { and epirubicin } \\
\text { or epirubicin } \\
\text { and docetaxel }\end{array}$ & $\begin{array}{l}\text { Validate } \\
\text { predictive } \\
\text { power of EMS }\end{array}$ \\
\hline $\begin{array}{l}22226 \\
\text { https://www.ncbi.nlm.nih.gov/ } \\
\text { geo/query/acc.cgi?acc=gse22226 }\end{array}$ & Esserman et al (21) & GPL1708 & $\begin{array}{l}\text { Breast cancer } \\
\text { samples }\end{array}$ & $\begin{array}{l}\text { Anthracycline, } \\
\text { cyclophosphamide } \\
\text { and taxane }\end{array}$ & $\begin{array}{l}\text { Validate } \\
\text { predictive } \\
\text { and prognostic } \\
\text { power of EMS }\end{array}$ \\
\hline $\begin{array}{l}22220 \\
\text { https://www.ncbi.nlm.nih.gov/ } \\
\text { geo/query/acc.cgi?acc=gse } 22220\end{array}$ & Buffa et al (22) & GPL6098 & $\begin{array}{l}\text { Breast cancer } \\
\text { samples }\end{array}$ & $\begin{array}{l}\text { Cyclophosphamide, } \\
\text { methotrexate } \\
\text { and 5-fluorouracil }\end{array}$ & $\begin{array}{l}\text { Validate } \\
\text { prognostic } \\
\text { power of EMS }\end{array}$ \\
\hline $\begin{array}{l}33926 \\
\text { https://www.ncbi.nlm.nih.gov/ } \\
\text { geo/query/acc.cgi?acc=gse33926 }\end{array}$ & Kuo et al (23) & GPL47265 & $\begin{array}{l}\text { Breast cancer } \\
\text { samples }\end{array}$ & N/A & $\begin{array}{l}\text { Validate } \\
\text { prognostic } \\
\text { power of EMS }\end{array}$ \\
\hline $\begin{array}{l}58644 \\
\text { https://www.ncbi.nlm.nih.gov/ } \\
\text { geo/query/acc.cgi?acc=gse } 58644\end{array}$ & Tofigh et al (24) & GPL6244 & $\begin{array}{l}\text { Breast cancer } \\
\text { samples }\end{array}$ & N/A & $\begin{array}{l}\text { Validate } \\
\text { prognostic } \\
\text { power of EMS }\end{array}$ \\
\hline $\begin{array}{l}7390 \\
\text { https://www.ncbi.nlm.nih.gov/ } \\
\text { geo/query/acc.cgi?acc=gse } 7390\end{array}$ & Desmedt et al (25) & GPL96 & $\begin{array}{l}\text { Breast cancer } \\
\text { samples }\end{array}$ & None & $\begin{array}{l}\text { Validate } \\
\text { prognostic } \\
\text { power of EMS }\end{array}$ \\
\hline $\begin{array}{l}45725 \\
\text { https://www.ncbi.nlm.nih.gov/ } \\
\text { geo/query/acc.cgi?acc=gse } 45725\end{array}$ & Wang et al (26) & GPL6883 & $\begin{array}{l}\text { Breast cancer } \\
\text { samples }\end{array}$ & None & $\begin{array}{l}\text { Validate } \\
\text { prognostic } \\
\text { power of EMS }\end{array}$ \\
\hline
\end{tabular}

GEO, Gene Expression Omnibus; EMS, ER-modified signature.

subtypes of breast cancer patients were analyzed based on their ER, PR and Her2 status (Table II).

The patients were hierarchically clustered based on their expression of EMS and the results revealed that the EMS exhibited an ability to discriminate the $\mathrm{ER}^{+}$patients (luminal $\mathrm{A}$ and B subtypes) from the ER patients (Her2 and triple-negative subtypes) in the two clusters (Fig. 2B). The accuracy was 91.6\% for $\mathrm{ER}^{+}$and $79.5 \%$ for $\mathrm{ER}^{-}$patients (Table II).
Patterns of pathway activity characterize $E R^{+}$and $E R^{-}$ breast cancers. To interpret the underlying biological significance of the EMS, its genes were analyzed in KEGG and GO (Fig. 1B, step 3, full list of pathways is not shown in the present study). Seven pathways that were enriched in at least three genes were selected: focal adhesion, metabolic pathways, extracellular matrix (ECM)-receptor interaction, response to steroid hormone stimulus, cell proliferation, 


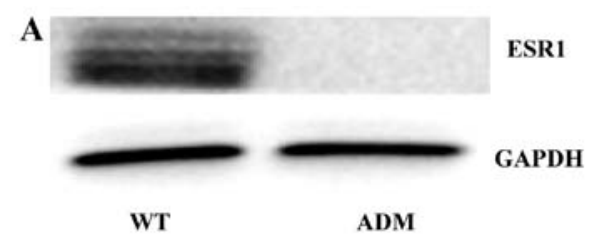

B
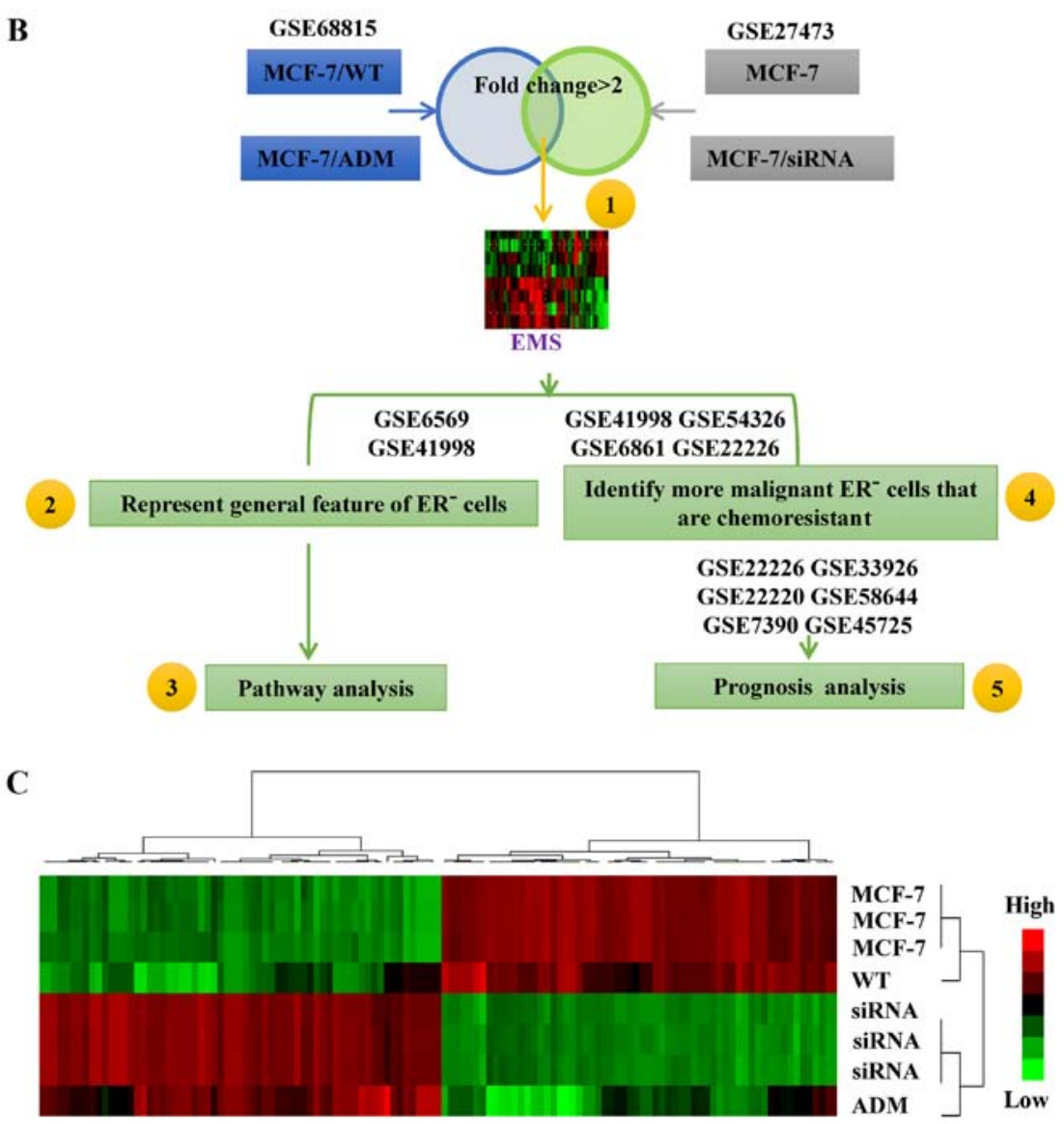

Figure 1. Generating the EMS. (A) Western blot analysis demonstrating that MCF-7/ADM cells (from GSE68815) lose their ER during chemotherapeutic challenge and gain chemoresistance. (B) Flowchart for developing and validating EMS. (C) Hierarchical clustering of genes in EMS from GSE68815 (WT and ADM) and GSE27473 (11) (MCF-7 and siRNA, three replicates). EMS, ER-modified signature; WT, wild-type; ADM, Adriamycin.

Table II. Molecular subtypes of breast cancer patients in GSE41998.

\begin{tabular}{|c|c|c|c|c|}
\hline \multirow[b]{2}{*}{ Subtypes } & \multirow{2}{*}{$\begin{array}{c}\begin{array}{c}\text { Summary } \\
\text { of GSE41998 }\end{array} \\
\text { Molecular status }\end{array}$} & \multirow[b]{2}{*}{ No. } & \multicolumn{2}{|c|}{$\begin{array}{c}\text { Classification } \\
\text { by EMS }\end{array}$} \\
\hline & & & $\mathrm{ER}^{+}$ & $\mathrm{ER}^{-}$ \\
\hline \multirow{3}{*}{$\begin{array}{l}\text { Luminal A } \\
(\mathrm{n}=111)\end{array}$} & $\mathrm{ER}^{+}, \mathrm{PR}^{+}, \mathrm{Her} 2^{-}$ & $\mathrm{n}=78$ & 72 & 6 \\
\hline & $\mathrm{ER}^{+}, \mathrm{PR}^{-}, \mathrm{Her} 2^{-}$ & $\mathrm{n}=22$ & 19 & 3 \\
\hline & $\mathrm{ER}^{-}, \mathrm{PR}^{+}, \mathrm{Her} 2^{-}$ & $\mathrm{n}=11$ & 5 & 6 \\
\hline \multirow{3}{*}{$\begin{array}{l}\text { Luminal B } \\
(n=12)\end{array}$} & $\mathrm{ER}^{+}, \mathrm{PR}^{+}, \mathrm{Her} 2^{+}$ & $\mathrm{n}=7$ & 7 & 0 \\
\hline & $\mathrm{ER}^{+}, \mathrm{PR}^{-}, \mathrm{Her} 2^{+}$ & $\mathrm{n}=1$ & 1 & 0 \\
\hline & $\mathrm{ER}^{-}, \mathrm{PR}^{+}, \mathrm{Her} 2^{+}$ & $n=4$ & 2 & 2 \\
\hline Her2 $(n=15)$ & $\mathrm{ER}^{-}, \mathrm{PR}^{-}, \mathrm{Her} 2^{+}$ & $\mathrm{n}=15$ & 8 & 7 \\
\hline $\mathrm{TN}(\mathrm{n}=141)$ & $\mathrm{ER}^{-}, \mathrm{PR}^{-}, \mathrm{Her} 2^{-}$ & $n=141$ & 20 & 121 \\
\hline
\end{tabular}

EMS, ER-modified signature; ER, estrogen receptor $\alpha$; PR, progesterone receptor; Her2, human epidermal growth factor receptor 2; TN, triple-negative. response to reactive oxygen species and calcium ion binding pathways. Then the probability of the pathway activity in each patient from GSE41998 was analyzed by multivariate logistic regression, where high pathway probability correlates with high pathway activity and vice versa (31). The hierarchical clustering of the pathway activity in each patient revealed that most of the $\mathrm{ER}^{+}$and $\mathrm{ER}^{-}$patients exhibited an opposite probability of pathway activity (Fig. 3A). The response to steroid hormone stimulus (p1), metabolic pathways (p2), ECM-receptor interaction (p3), focal adhesion (p4), cell proliferation (p5), response to reactive oxygen species (p6) and calcium ion binding pathways (p7) exhibited higher activity in ER breast cancer patients.

In addition to the clusters of samples, patterns of pathway co-regulation were identified using Pearson's correlation (Fig. 3B); focal adhesion vs. cell proliferation ( $\mathrm{r}=0.926)$, focal adhesion vs. calcium ion binding pathways $(\mathrm{r}=0.927)$ and cell proliferation vs. calcium ion binding pathways $(r=0.876)$ were highly correlated. 

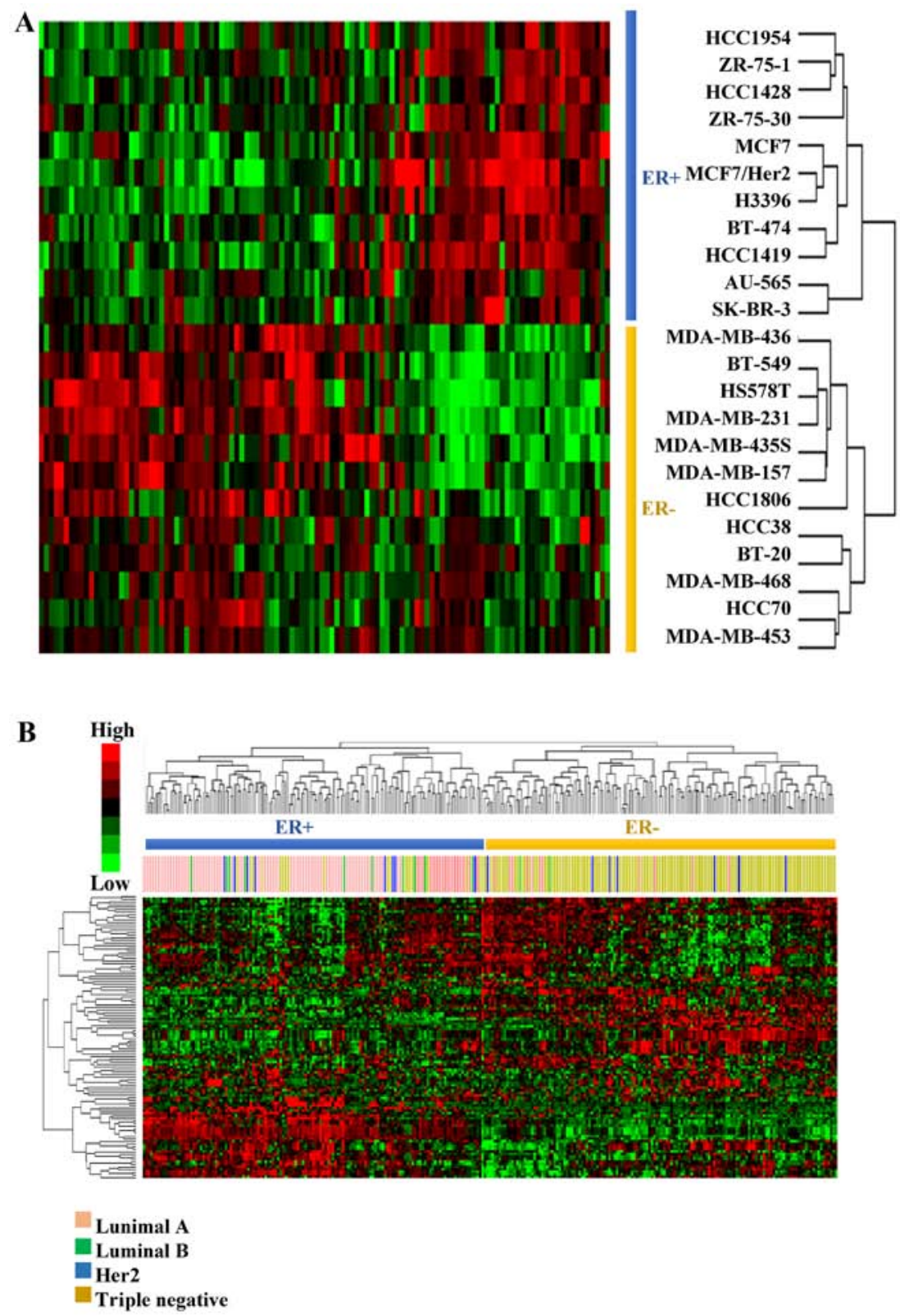

Figure 2. EMS presents basic features of ER' breast cancer cells. (A) Hierarchical clustering of genes in EMS from different breast cancer cell lines from GSE6569 (18). (B) Hierarchical clustering of genes in EMS from different breast cancer cells from GSE41998 (19). The molecular subtype of breast cancer of each patient is shown in a different color (red, luminal A; green, luminal B; blue, Her2; brown, triple-negative). EMS, ER-modified signature; ER, estrogen receptor $\alpha$.

EMS predicts chemoresistant features in ER- cells. As above-mentioned, we postulated that the EMS derived from the MCF-7/ADM cells may embed the gene-expression features of chemoresistance in ER- breast cancer cells (Fig. 1B, step 4). To examine this hypothesis, the EMS expression was analyzed in two chemoresistant ER ${ }^{-}$cell lines and compared with their chemosensitive controls (MDA-MB-231 and SKBR3 from GSE54326). This exhibited a $>1.5$-fold change in $67.8 \%$ of the EMS genes in the MDA-MB-231 cells and $62.5 \%$ in the SKBR3 cells (Fig. 4A). Then the EMS gene-expression values were used to calculate the probability of resistance and sensitivity in these cells by Bayesian binary regression analysis. As a result, both chemoresistant lines yielded $100 \%$ probability of chemoresistance, while both chemosensitive lines showed $0 \%$ probability of chemoresistance (Fig. 4A). Furthermore, the accuracy of probability of chemoresistance in these cells was evaluated with the maximum tolerated doses provided by the GSE54326 regardless of the cell types. The results revealed that the higher probabilities of chemoresistance were positively correlated with the maximum tolerated doses for the cells that were analyzed by Pearson's correlation assay (Fig. 4B). However, we need to point out that the sample size used in this study is small and although the probability of chemoresistance demonstrates a correlation with the tolerable doses of the cell lines, further studies with more chemoresistant or sensitive cell lines are required to calculate more accurately the Pearson's correlation coefficience. Collectively, these results strongly indicate that EMS can efficiently discriminate chemoresistant and sensitive $\mathrm{ER}^{-}$breast cancer cell lines.

To identify the chemoresistant cases among the ER- breast cancer population, the EMS was validated in clinical samples 

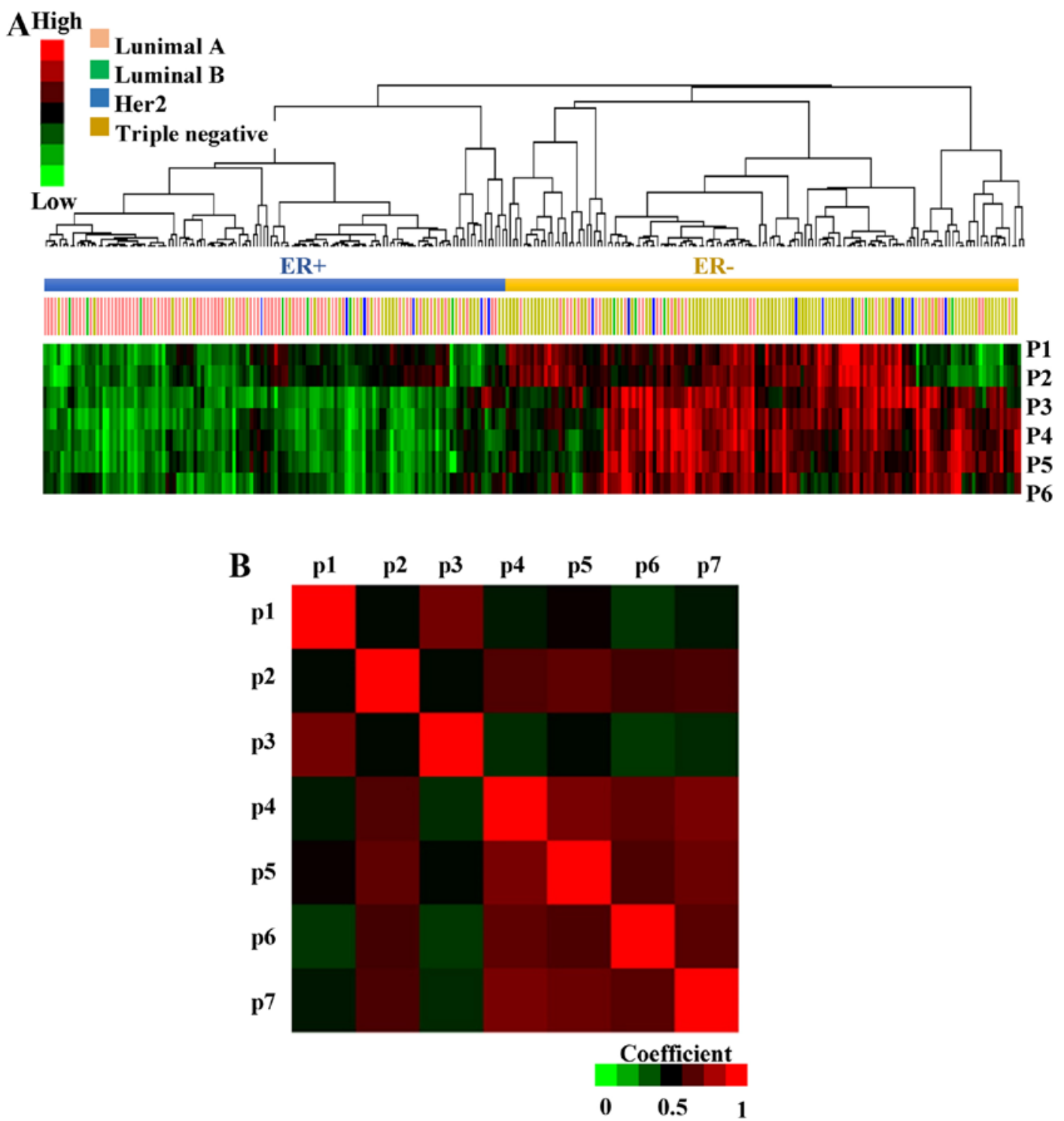

Figure 3. Probability of pathway activity in $\mathrm{ER}^{+}$and ER- breast cancer cells. (A) The probability of pathway activity for each patient from GSE41998 was analyzed by multivariate logistic regression and then by hierarchical clustering. Seven pathways were used for analysis: steroid hormone stimulus (p1), metabolic pathways (p2), ECM-receptor interaction (p3), focal adhesion (p4), cell proliferation (p5), response to reactive oxygen species (p6) and calcium ion binding pathways (p7). The molecular subtype of breast cancer for each patient is shown in different colors. (B) Patterns of pathway co-regulation. The co-regulation was analyzed with Pearson's correlation. ER, estrogen receptor $\alpha$; ECM, extracellular matrix.

from the NCT00455533 phase II trial (GSE41998) (19), the EORTC 10994 phase III trial (GSE6861) (20) and the I-SPY 1 trial (GSE22226) (21). Biopsy specimens from these datasets were collected before any systematic treatment. Subsequently, the patients underwent anthracycline-based chemotherapy. A pathologically complete response to chemotherapy was defined as chemosensitive and residual disease was defined as chemoresistant. The Bayesian binary regression was used to develop a model that differentiates a pattern of anthracycline sensitivity from that of resistance based on the EMS expression. In all three datasets, the EMS demonstrated the ability to discriminate the chemoresistant from the chemosensitive patients. The overall accuracy in predicting chemoresistance was $96.27 \%$ (EMS sensitivity) and chemosensitivity was 97.2\% (EMS specificity) (Fig. 4C-E).

The discriminative ability of EMS was also reflected in the ROC curve, which is an important index of the accuracy of a clinical test. The resistant and sensitive cases defined by the EMS in all three groups were analyzed by ROC curves and the corresponding AUC was 0.988 (Fig. 4F), suggesting that the EMS is good at discriminating both chemoresistant and chemosensitive patients.

Prognosis can be estimated by EMS. Since chemoresponse is important for determining the survival status of a patient, the EMS may also predict the prognosis of ER breast cancer patients receiving chemotherapy (Fig. 1B, step 5). Therefore, the ability of EMS to estimate prognosis was assessed in four independent datasets containing both $\mathrm{ER}^{+}$and $\mathrm{ER}^{-}$breast cancer patients, from which ER patients were chosen for analysis. Firstly we analyzed GSE22226 (21), which records both the chemoresponse and the RFS status of each ER' patient. After the patients in GSE22226 were grouped according to their chemoresponse predicted by EMS, the Kaplan-Meier 
A

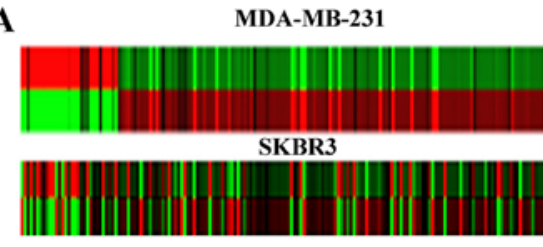

B

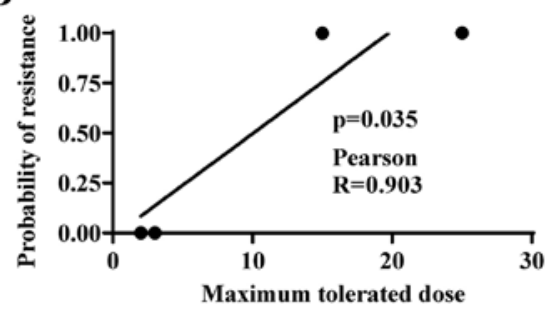

D

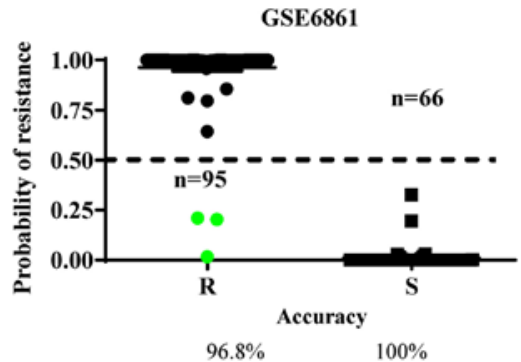

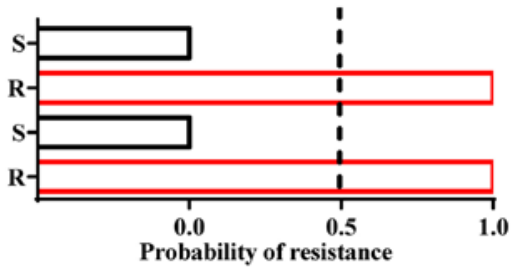

C.

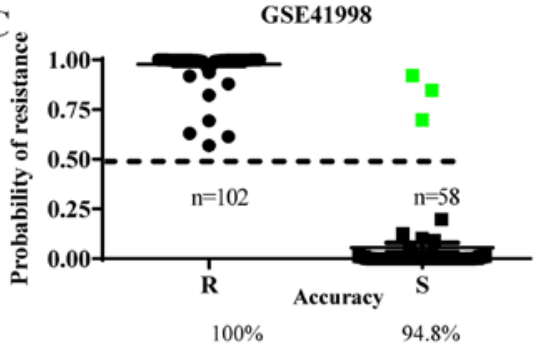

E

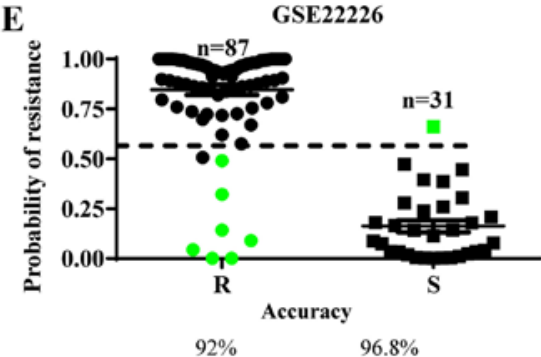

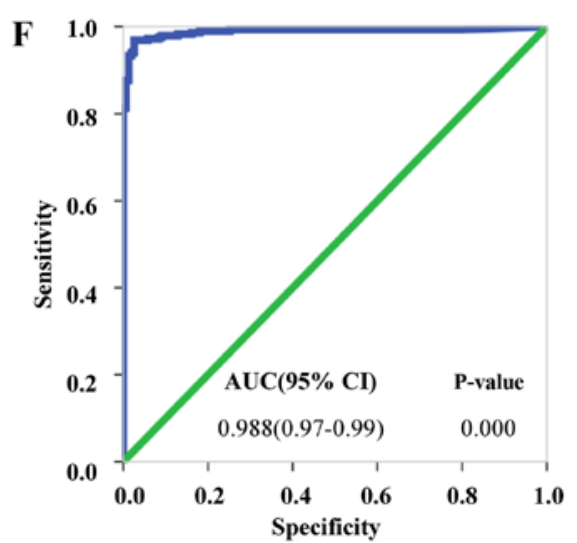

Figure 4. EMS predicts chemoresistance in ER breast cancer cells. (A) The heat maps of EMS expression in resistant and sensitive MDA-MB-231 and SKBR3 cells from GSE54326 (left panel). The probability of chemoresistance in MDA-MB-231 and SKBR3 cells from GSE54326 analyzed by the Bayesian binary regression (right panel). (B) The Pearson's correlation demonstrating that the probability of chemoresistance in the MDA-MB-231 and SKBR3 cells was positively related to the maximum tolerated dose. (C-E) The probability of chemoresistance predicted by Bayesian binary regression in GSE41998 (19), 6861 (20) and 22226 (21). The cut off was set at 0.5 . Misclassified individuals are shown in green. (F) The area under the receiver operating characteristic curve (AUC) showing how well the signature predicted chemoresistance. EMS, ER-modified signature; ER, estrogen receptor $\alpha$.

analysis revealed that those $\mathrm{ER}^{-}$patients who were predicted to be chemoresistant had a lower rate of RFS than the patients predicted to be chemosensitive (Fig. 5A).

Subsequently the prognostic test of EMS in ER- patients was performed in three datasets [GSE22220 (22), GSE33926 (23) and GSE58644 (24)]. ER patients in these datasets received different regimes of chemotherapy and their DRFS or RFS were recorded. Since there was no information on the chemoresponse in these patients, the Bayesian assay could not be performed without predetermined data to train the regression process. Instead, based on the EMS expression, patients were firstly classified into two groups by k-means clustering and their chemoresponse was determined by calculating the correlation with chemoresistant ER- cells in GSE54326. ER- patients who were predicted to be chemoresistant also had a lower RFS rate (Fig. 5B-D).

Subsequenlty a meta-analysis was performed to combine the results from prognosis analysis in the above-mentioned datasets. The ORs for death events were calculated and the forest plots revealed that the average ORs for $\mathrm{ER}^{-}$patients predicted to be chemoresistant were $>1$ in each dataset (Fig. 5E). In addition, the overall OR for ER- patients predicted to be chemoresistant was 3.22, indicating that these EMS-defined chemoresistant $\mathrm{ER}^{-}$patients had a significantly lower probability of survival. 
A

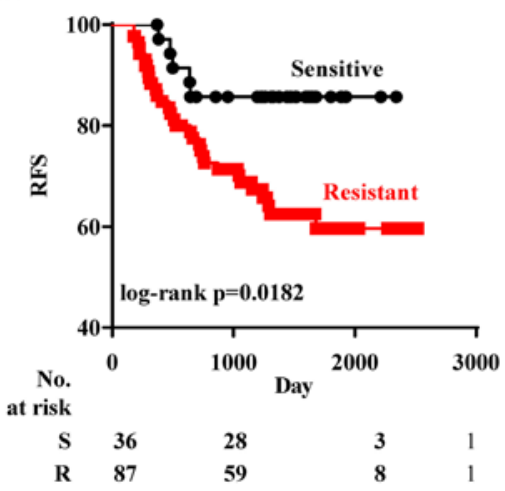

C

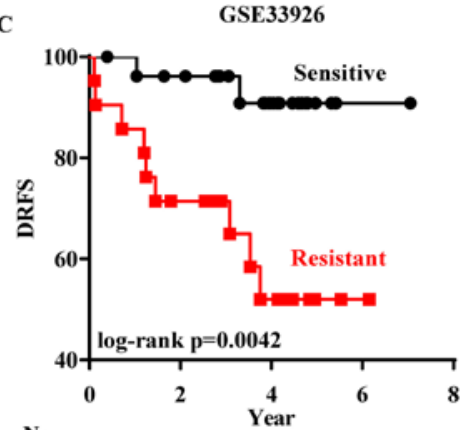

B

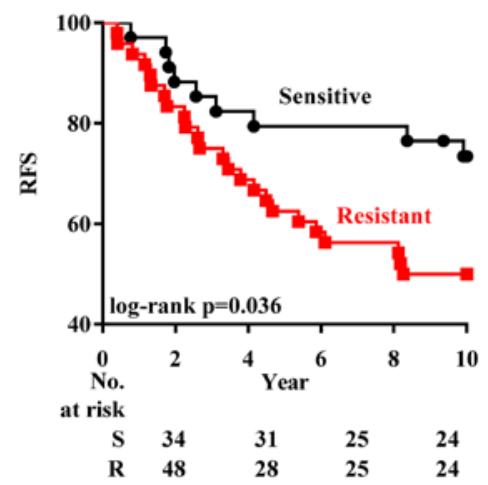

D

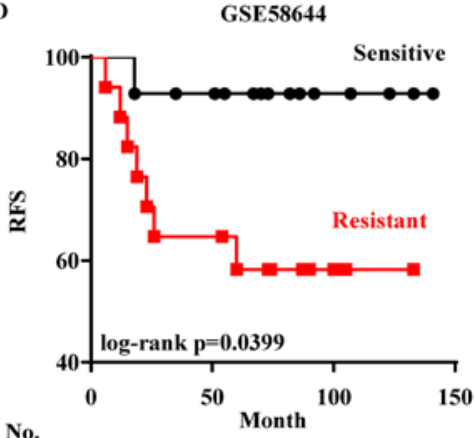

No.

at risk

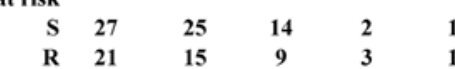

S 14

$\begin{array}{llll}14 & 13 & 5 & 1 \\ 17 & 12 & 6 & 1\end{array}$

E

OR

Weight

$\underset{95 \%}{O}$

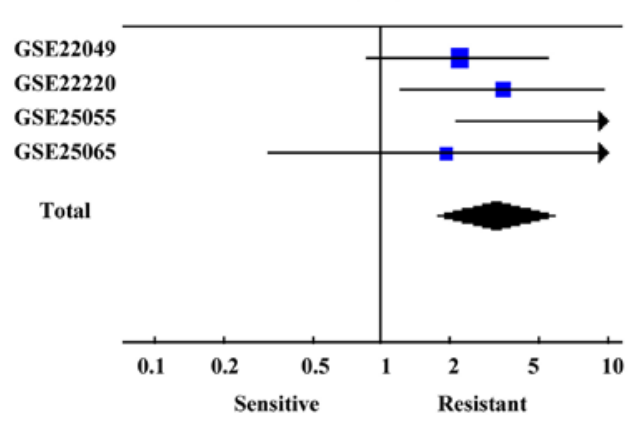

$45.51 \quad 2.21(0.875 .60)$

$33.98 \quad 3.43(1.21,9.72)$

$7.02 \quad 11.25(2.13,59.38)$

$13.48 \quad 1.93(0.32,11.74)$

100

$3.22(1.78,5.82)$

F

GSE7390

GSE45725
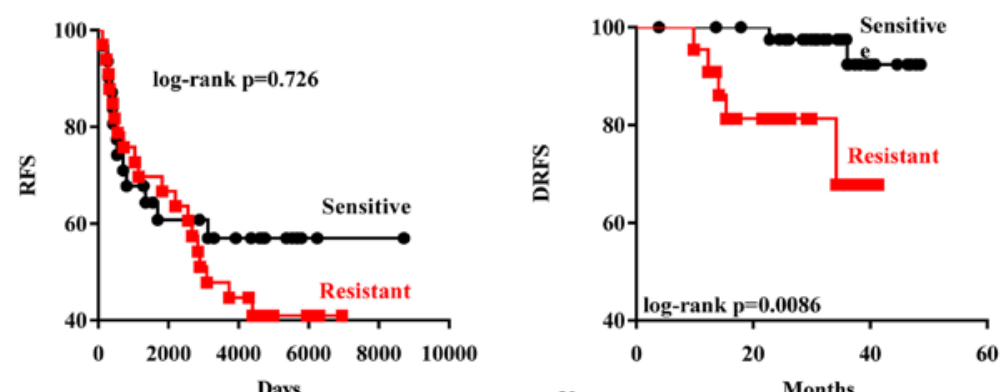

No.
at risk
S

Days

$\begin{array}{lllllll}R & 33 & 23 & 15 & 5 & 1\end{array}$

at risk

$\begin{array}{llll}43 & 41 & 12 & 1\end{array}$

Figure 5. Survival analysis of EMS. (A) Kaplan-Meier analysis of the RFS in ER patients from GSE22226 receiving anthracycline-based chemotherapy. The patients were grouped into resistant or sensitive by the EMS and the difference in RFS was calculated. (B-D) Kaplan-Meier analysis of the RFS and DRFS in ER patients from GSE22220 (22) (B), 33926 (23) (C) and 58644 (24) (D) receiving different chemotherapeutic regimes. The patients were grouped by k-means clustering and their chemoresponse was determined by calculating the correlation with chemoresistant ER cells in GSE54326. (E) Forest plots showing the ability of EMS to predict clinical outcomes (measured as death events) in GSE22226 (21), 22220 (22), 33926 (23) and 58644 (24) by meta-analysis. Odds ratios (ORs) for each dataset are plotted as horizontal bars; the length of the bar represents the $95 \%$ confidence interval and the bars can be compared vertically between datasets. Diamond, total OR in all cases; weight, relative size of each dataset. (F) Kaplan-Meier analysis of RFS and DRFS in ER patients from GSE7390 (25) and 45725 (26) that did not receive chemotherapy. The patients were grouped by k-means clustering and their chemoresponse was determined by calculating the correlation with chemoresistant ER' cells in GSE54326. EMS, ER-modified signature; ER, estrogen receptor $\alpha$; RFS, relapse-free survival; DRFS, distant relapse-free survival. 
Finally, the prognostic ability of EMS was validated in two cohorts, in which the patients did not receive chemotherapy after surgery [GSE7390 (25) and GSE45725 (26)]. Although the EMS-predicted chemoresistant patients exhibited lower RFS and DRFS ratios, the differences were not significant in GSE7390 (Fig. 5F).

\section{Discussion}

Switching from $\mathrm{ER}^{+}$to $\mathrm{ER}^{-}$status is a way for cancer cells to cope with cytotoxic stress. However the subsequent ER- cells are not simply the same as primary ER ${ }^{-}$cells and may be more aggressive in the process of adapting to severe circumstances. Therefore, investigating the changes in gene expression patterns may provide a list of genes associated with a more malignant phenotype in $\mathrm{ER}^{-}$cancer cells. In the present study, we aimed to identify gene expression changes during both ER-loss and chemoresistance-gain in breast cancer cells.

Firstly we found 105 genes in EMS by cross-matching two pairs of breast cancer cell lines with ER-loss (GSE68815 and GSE27473). By comparison with $\mathrm{ER}^{+}$breast cancer cells, the EMS reflected the basic features of ER cells both in different breast cancer cell lines and clinical samples because they significantly changed during the disappearance of ER. The expression of 51 genes among the 105 genes, was significantly increased and these genes may be activated to complement the ER function and may be important for inducing new features of $\mathrm{ER}^{-}$cells, such as chemoresistance. Therefore, they provide new targets for treating breast cancer after ER-loss. For example, BCAT1 was one of the most markedly increased genes in ER cells from both GSE68815 and GSE27473. BCAT1 promotes the proliferation and metastasis of cancer cells $(32,33)$, therefore inhibiting it may decrease the malignant features of $\mathrm{ER}^{-}$cancer cells. On the other hand, the expression of 54 genes was significantly decreased, suggesting that ER may depend on these genes to mediate breast cancer signaling in $\mathrm{ER}^{+}$breast cancers. For example, PBX1 was one of the most markedly decreased genes in $\mathrm{ER}^{-}$cells. PBX1 is essential for the ER $\alpha$-mediated transcriptional response and promotes aggressiveness in breast cancers (34). Therefore, PBX1 and other genes in the 54-gene list provide new targets for treating $\mathrm{ER}^{+}$breast cancers.

ER breast cancers are more frequently high grade and have worse prognosis compared with $\mathrm{ER}^{+}$breast cancers, although there is still a group of ER patients who have good clinical outcome within the ER ${ }^{-}$population. The EMS was enriched in the KEGG and GO pathways, therefore giving a summary of the signaling pathways both essential in the $\mathrm{ER}^{+} / \mathrm{ER}^{-}$transition and the ER- cell malignant transition, which included development of chemoresistance. Changes in focal adhesion and ECM-receptor interaction pathways enable cancer cells to communicate with ECM and gain high motility, thus ER cells are more aggressive and metastasize more easily, enabling them to escape from toxic niches (35). Changes in the response to reactive oxygen species also induce cancer progression, metastasis and changes in drug metabolism (36). In addition the cell proliferation and calcium ion binding pathways could not only promote cancer cells to adapt to new signaling pathways to survive during ER loss, but also help the malignant
ER cells to endure cytotoxic therapies and become highly metastatic $(37,38)$. Therefore, in the present study we provided a link between the predicted pathway activity and the ER transition-induced genomic changes and emphasized several essential pathways that can form the basis for the rational design of therapeutic regimes for breast cancer patients with ER-loss after a first-round failure of therapy.

Subsequently the Pearson's correlation between each pathway during the ER transition was calculated and the focal adhesion, the calcium ion binding pathways and the cell proliferation revealed significantly high correlations with each other. This result highlighted a network that, during ER-loss and the malignant transition of breast cancer cells, endows them with high motility and invasiveness by changing the focal adhesion pathway, however they must preserve high viability via the calcium ion binding and the cell proliferation pathways to avoid such factors as anoikis, immune surveillance and chemotherapeutic toxicity. In addition, in the absence of ER-related cell survival signaling (39) to maintain proliferation, cancer cells need high motility in order to escape from the disadvantageous microenvironment during therapies such as anti-hormone and chemotherapeutic regimes.

Furthermore, since the EMS was developed based on chemoresistant ER breast cancer MCF-7/ADM cells, the genes in the EMS are likely to be required for the development of chemoresistance. We revealed that the EMS discriminated the chemoresistant from the chemosensitive ER- breast cancer cell lines MDA-MB-231 and SKBR3 and we expect further studies to elucidate the discriminative power of EMS in more ER- breast cancer cell lines. These studies will not only help to determine the chemoresponse of one ER breast cancer cell line with its gene expression profile, but also provide information about the tolerable doses of the cells, if the accurate correlation coefficience between probabilities of chemoresistance and maximum tolerated dose is calculated. Subsequently, we demonstrated the ability of EMS to predict chemoresistance in patients treated with anthracycline-based chemotherapies, which is one of the most widely used regimes for ER ${ }^{-}$breast cancer patients (40). We selected these datasets as the MCF-7/ADM cells confronted the challenge from an anthracycline agent (ADM) to develop chemoresistance, thus anthracycline-treated patients may share similar chemoresistant signaling pathways. Furthermore, the biopsy specimens in these datasets were collected before any systematic treatment and their gene expression profiles were analyzed by microarray, thus if the EMS is validated in a larger sample size in the future, it may help in the clinical choice of chemotherapeutic regimes. In addition, the Her 2 and TNBC are two distinct subgroups in $\mathrm{ER}^{-}$breast cancers and show different chemoresponses and clinical outcomes. In the present study, we lacked an efficient number of Her2 patients and could not conclude whether the EMS-related chemoresistance correlates with these two subgroups. However, in future studies, more clinical samples can be collected to demonstrate this correlation.

In addition, related to the ability of EMS to predict the chemoresponse, the prognosis of anthracycline-treated ER patients could be estimated by the EMS. We also examined the prognostic power of EMS in ER- breast cancer patients treated with different chemotherapeutic regimes but without anthracycline agents and observed that it is effective in estimating 
the prognosis of these ER- patients. Such good discriminative capacity of the signature to different chemotherapeutic regimes in ER- patients may be due to the MCF-7/ADM cells exhibiting features of resistance to different types of chemotherapeutic agents (13), therefore the EMS derived from them may involve mechanisms of resistance common to other agents. Indeed, in the enriched GO and KEGG of EMS, pathways shared by chemoresistance of different types of chemotherapeutic agents were significantly enriched, including mechanisms such as overexpression of p-glycoprotein $(41,42)$ and glutathione S-transferase P1 (44) and activation of the epithelial-mesenchymal transition pathway $(44,45)$. Therefore, the genes in EMS may also provide a basis for finding important mechanisms of chemoresistance and related factors that affect prognosis.

Finally, to assess whether EMS could estimate the prognosis for $\mathrm{ER}^{-}$breast cancers that are intrinsically more aggressive, regardless of therapy, we examined the impact of EMS on RFS and DRFS in two datasets where the patients did not receive either chemotherapy or hormonal therapy. The EMS could not separate a good from a bad prognosis at a significant level, indicating that it is predictive of treatment response rather than prognostic of survival.

In conclusion, in the present study we developed a gene expression signature that can identify subgroups of ER- breast cancer cells that are chemoresistant.

\section{Acknowledgements}

The present study was supported by grants from the National Natural Science Foundation of China (no. 31200126), the Natural Science Foundation of Jiangsu Province (BK20141109) and the Natural Science Foundation for Distinguished Young Scholars of Jiangsu Province (BK20140004). We would like to thank Dr I.C. Bruce for reading the manuscript.

\section{References}

1. Berry DA, Cronin KA, Plevritis SK, Fryback DG, Clarke L, Zelen M, Mandelblatt JS, Yakovlev AY, Habbema JD and Feuer EJ; Cancer Intervention and Surveillance Modeling Network (CISNET) Collaborators: Effect of screening and adjuvant therapy on mortality from breast cancer. N Engl J Med 353: 1784-1792, 2005.

2. Johnston SR: New strategies in estrogen receptor-positive breast cancer. Clinical Cancer Res 16: 1979-1987, 2010.

3. Lo S and Johnston SR: Novel systemic therapies for breast cancer. Surg Oncol 12: 277-287, 2003.

4. Gutierrez MC, Detre S, Johnston S, Mohsin SK, Shou J, Allred DC, Schiff R, Osborne CK and Dowsett M: Molecular changes in tamoxifen-resistant breast cancer: Relationship between estrogen receptor, HER-2, and p38 mitogen-activated protein kinase. J Clin Oncol 23: 2469-2476, 2005.

5. Lee SH, Chung MA, Quddus MR, Steinhoff MM and Cady B: The effect of neoadjuvant chemotherapy on estrogen and progesterone receptor expression and hormone receptor status in breast cancer. Am J Surg 186: 348-350, 2003.

6. Yang X, Phillips DL, Ferguson AT, Nelson WG, Herman JG and Davidson NE: Synergistic activation of functional estrogen receptor (ER)-alpha by DNA methyltransferase and histone deacetylase inhibition in human ER-alpha-negative breast cancer cells. Cancer Res 61: 7025-7029, 2001.

7. Kuukasjärvi T, Kononen J, Helin H, Holli K and Isola J: Loss of estrogen receptor in recurrent breast cancer is associated with poor response to endocrine therapy. J Clin Oncol 14: 2584-2589, 1996

8. Won HY, Lee JY, Shin DH, Park JH, Nam JS, Kim HC and Kong G: Loss of Mel-18 enhances breast cancer stem cell activity and tumorigenicity through activating Notch signaling mediated by the Wnt/TCF pathway. FASEB J 26: 5002-5013, 2012.
9. Gruvberger S, Ringnér M, Chen Y, Panavally S, Saal LH, Borg A, Fernö M, Peterson C and Meltzer PS: Estrogen receptor status in breast cancer is associated with remarkably distinct gene expression patterns. Cancer Res 61: 5979-5984, 2001.

10. Niemeier LA, Dabbs DJ, Beriwal S, Striebel JM and Bhargava R: Androgen receptor in breast cancer: Expression in estrogen receptor-positive tumors and in estrogen receptornegative tumors with apocrine differentiation. Mod Pathol 23: 205-212, 2010.

11. Al Saleh S, Al Mulla F and Luqmani YA: Estrogen receptor silencing induces epithelial to mesenchymal transition in human breast cancer cells. PLoS One 6: e20610, 2011.

12. Luqmani YA, Al Azmi A, Al Bader M, Abraham G and El Zawahri M: Modification of gene expression induced by siRNA targeting of estrogen receptor alpha in MCF7 human breast cancer cells. Int J Oncol 34: 231-242, 2009.

13. Ma X, Cai Y, He D, Zou C, Zhang P, Lo CY, Xu Z, Chan FL, Yu S, Chen Y, et al: Transient receptor potential channel TRPC5 is essential for P-glycoprotein induction in drug-resistant cancer cells. Proc Natl Acad Sci USA 109: 16282-16287, 2012.

14. Ma X, Chen Z, Hua D, He D, Wang L, Zhang P, Wang J, Cai Y, Gao C, Zhang X, et al: Essential role for TrpC5-containing extracellular vesicles in breast cancer with chemotherapeutic resistance. Proc Natl Acad Sci USA 111: 6389-6394, 2014.

15. He DX, Gu XT, Jiang L, Jin J and Ma X: A methylation-based regulatory network for microRNA $320 \mathrm{a}$ in chemoresistant breast cancer. Mol Pharmacol 86: 536-547, 2014.

16. He DX, Gu XT, Li YR, Jiang L, Jin J and Ma X: Methylation-regulated miRNA-149 modulates chemoresistance by targeting NDST1 in human breast cancer. FEBS J 281: 4718-4730, 2014.

17. Jiang L, He D, Yang D, Chen Z, Pan Q, Mao A, Cai Y, Li X, Xing H, Shi M, et al: MiR-489 regulates chemoresistance in breast cancer via epithelial mesenchymal transition pathway. FEBS Lett 588: 2009-2015, 2014.

18. Huang F, Reeves K, Han X, Fairchild C, Platero S, Wong TW, Lee F, Shaw P and Clark E: Identification of candidate molecular markers predicting sensitivity in solid tumors to dasatinib: Rationale for patient selection. Cancer Res 67: 2226-2238, 2007.

19. Horak CE, Pusztai L, Xing G, Trifan OC, Saura C, Tseng LM, Chan S, Welcher R and Liu D: Biomarker analysis of neoadjuvant doxorubicin/cyclophosphamide followed by ixabepilone or Paclitaxel in early-stage breast cancer. Clin Cancer Res 19: 1587-1595, 2013.

20. Bonnefoi H, Potti A, Delorenzi M, Mauriac L, Campone M, Tubiana-Hulin M, Petit T, Rouanet P, Jassem J, Blot E, et al: Retraction - Validation of gene signatures that predict the response of breast cancer to neoadjuvant chemotherapy: A substudy of the EORTC 10994/BIG 00-01 clinical trial. Lancet Oncol 12: 116, 2011.

21. Esserman LJ, Berry DA, Cheang MC, Yau C, Perou CM, Carey L, DeMichele A, Gray JW, Conway-Dorsey K, Lenburg ME, et al; I-SPY 1 TRIAL Investigators: Chemotherapy response and recurrence-free survival in neoadjuvant breast cancer depends on biomarker profiles: Results from the I-SPY 1 TRIAL (CALGB 150007/150012; ACRIN 6657). Breast Cancer Res Treat 132: 1049-1062, 2012.

22. Buffa FM, Camps C, Winchester L, Snell CE, Gee HE, Sheldon H, Taylor M, Harris AL and Ragoussis J: microRNA-associated progression pathways and potential therapeutic targets identified by integrated mRNA and microRNA expression profiling in breast cancer. Cancer Res 71: 5635-5645, 2011.

23. Kuo WH, Chang YY, Lai LC, Tsai MH, Hsiao CK, Chang KJ and Chuang EY: Molecular characteristics and metastasis predictor genes of triple-negative breast cancer: A clinical study of triple-negative breast carcinomas. PLoS One 7: e45831, 2012.

24. Tofigh A, Suderman M, Paquet ER, Livingstone J, Bertos N, Saleh SM, Zhao H, Souleimanova M, Cory S, Lesurf R, et al: The prognostic ease and difficulty of invasive breast carcinoma. Cell Rep 9: 129-142, 2014.

25. Desmedt C, Piette F, Loi S, Wang Y, Lallemand F, Haibe-Kains B, Viale G, Delorenzi M, Zhang Y, d'Assignies MS, et al; TRANSBIG Consortium: Strong time dependence of the 76-gene prognostic signature for node-negative breast cancer patients in the TRANSBIG multicenter independent validation series. Clin Cancer Res 13: 3207-3214, 2007.

26. Wang DY, Done SJ, Mc Cready DR and Leong WL: Validation of the prognostic gene portfolio, ClinicoMolecular Triad Classification, using an independent prospective breast cancer cohort and external patient populations. Breast Cancer Res 16: R71, 2014. 
27. He DX, Xia YD, Gu XT, Jin J and Ma X: A transcription/translation-based gene signature predicts resistance to chemotherapy in breast cancer. J Pharm Biomed Anal 102: 500-508, 2015.

28. Hastie T, Sleeper L and Tibshirani R: Flexible covariate effects in the proportional hazards model. Breast Cancer Res Treat 22: 241-250, 1992

29. Lachenbruch PA: Discriminant diagnostics. Biometrics 53: 1284-1292, 1997.

30. He DX, Xia YD, Gu XT, Jin J and Ma X: A 20-gene signature in predicting the chemoresistance of breast cancer to taxane-based chemotherapy. Mol Biosyst 10: 3111-3119, 2014.

31. Gatza ML, Lucas JE, Barry WT, Kim JW, Wang Q, Crawford MD, Datto MB, Kelley M, Mathey-Prevot B, Potti A, et al: A pathway-based classification of human breast cancer. Proc Nat Acad Sci U S A 107: 6994-6999, 2010.

32. Tönjes M, Barbus S, Park YJ, Wang W, Schlotter M,Lindroth AM, Pleier SV, Bai AHC, Karra D, Piro RM, et al: BCAT1 promotes cell proliferation through amino acid catabolism in gliomas carrying wild-type IDH1. Nat Med 19: 901-908, 2013.

33. Zhou W, Feng X, Ren C, Jiang X, Liu W, Huang W, Liu Z, Li Z, Zeng L, Wang L, et al: Over-expression of BCAT1, a c-Myc target gene, induces cell proliferation, migration and invasion in nasopharyngeal carcinoma. Mol Cancer 12: 53, 2013.

34. Magnani L, Ballantyne EB, Zhang X and Lupien M: PBX1 genomic pioneer function drives $\mathrm{ER} \alpha$ signaling underlying progression in breast cancer. PLoS Genet 7: e1002368, 2011.

35. Emery LA, Tripathi A, King C, Kavanah M, Mendez J, Stone MD, de las Morenas A, Sebastiani P and Rosenberg CL: Early dysregulation of cell adhesion and extracellular matrix pathways in breast cancer progression. Am J Pathol 175: 1292-1302, 2009.
36. Schumacker PT: Reactive oxygen species in cancer: a dance with the devil. Cancer Cell 27: 156-157, 2015.

37. Yang H, Zhang Q, He J and Lu W: Regulation of calcium signaling in lung cancer. J Thorac Dis 2: 52-56, 2010.

38. Monteith GR, McAndrew D, Faddy HM and Roberts-Thomson SJ: Calcium and cancer: Targeting $\mathrm{Ca}^{2+}$ transport. Nat Rev Cancer 7: 519-530, 2007.

39. Sommer S and Fuqua SA: Estrogen receptor and breast cancer. Semin Cancer Biol 11: 339-352, 2001.

40. Isakoff SJ: Triple-negative breast cancer: Role of specific chemotherapy agents. Cancer J 16: 53-61, 2010.

41. Bell DR, Gerlach JH, Kartner N, Buick RN and Ling V: Detection of P-glycoprotein in ovarian cancer: A molecular marker associated with multidrug resistance. J Clin Oncol 3: 311-315, 1985.

42. Li X, Li JP, Yuan HY, Gao X, Qu XJ, Xu WF and Tang W: Recent advances in P-glycoprotein-mediated multidrug resistance reversal mechanisms. Methods Find Exp Clin Pharmacol 29: 607-617, 2007.

43. Townsend DM and Tew KD: The role of glutathione-S-transferase in anti-cancer drug resistance. Oncogene 22: 7369-7375, 2003.

44. Lee JM, Dedhar S, Kalluri R and Thompson EW: The epithelial-mesenchymal transition: New insights in signaling, development, and disease. J Cell Biol 172: 973-981, 2006.

45. Polyak K and Weinberg RA: Transitions between epithelial and mesenchymal states: Acquisition of malignant and stem cell traits. Nat Rev Cancer 9: 265-273, 2009. 